\title{
Operative or conservative treatment in patients with Rockwood type III acromioclavicular dislocation: a systematic review and update of current literature
}

\author{
Koos Korsten • Amy C. Gunning • Luke P. H. Leenen
}

Received: 20 September 2013 / Accepted: 23 September 2013 /Published online: 31 October 2013

(C) Springer-Verlag Berlin Heidelberg 2013

\begin{abstract}
Purpose Despite previous studies the management of Rockwood type III acromioclavicular (AC) dislocations remains controversial and the debate continues about whether patients with Rockwood type III AC injuries should be treated conservatively or operatively. In this study, we will review the current literature and present an overview of the outcome of conservative versus operative treatment of Rockwood type III dislocations.

Methods The Preferred Reporting Items for Systematic Reviews and Meta-Analyses (PRISMA) guidelines was used to conduct this review. A systematic search was performed in the Pubmed, Cochrane library, Embase, Scopus and Cumulative Index to Nursing and Allied Health Literature databases. Titles and abstracts were screened using predefined criteria and articles were critically appraised on relevance and validity.

Results After critical appraisal eight articles were included in the study. The objective and subjective shoulder function outcome was better in the operative group, especially in young adults, though the rate of complications and radiographic abnormalities were higher. The rehabilitation time was shorter in the conservative group, however the cosmetic outcome was worse.

Conclusions This review showed no conclusive evidence for the treatment of Rockwood type III AC dislocations. Overall, physically active young adults seem to have a slight advantage in outcome when treated operatively.
\end{abstract}

Keywords Acromioclavicular $\cdot$ Rockwood $\cdot$ III/3 · Conservative $\cdot$ Operative $\cdot$ Dislocation

K. Korsten $(\bowtie) \cdot$ A. C. Gunning $\cdot$ L. P. H. Leenen

Department of Surgery, University Medical Center Utrecht, Suite G04.228, Heidelberglaan 100, 3584 CX Utrecht, The Netherlands e-mail: k.korsten@umcutrecht.nl

\section{Introduction}

The management of Rockwood grade III acromioclavicular (AC) dislocations remains controversial. Conservative treatment shows excellent results and a painless shoulder function. However, the dislocation is not actively reduced and will maintain in a prominent position in the majority of the patients. Furthermore, some patients suffer from chronic instability and pain [1,2]. These shortcomings might be prevented when treated operatively. With surgical treatment the dislocation, with the upstanding collar bone, can be actively reduced to achieve anatomical correction and the best function and shape of the shoulder. However, this treatment might compromise the function of the shoulder [1, 3].

In most cases the choice of treatment depends on the preference of the treating surgeon or the choice of the patients: young active patients prefer surgery and elderly patients prefer conservative treatment. Choice of treatment is even geographically determined. In Germany the majority are treated surgically in contrast to the United States of America where conservative treatment is preferred [4].

Also in the literature, there is still no consensus regarding the treatment of Rockwood type III AC dislocations. The difficulty lies in the different definitions of grade III AC dislocations used in the current studies. There are multiple classifications for the description of AC dislocations. Common classifications for AC dislocations are the Allman [5], Tossy et al. [6] and Rockwood et al. [7] classifications. Allman and Tossy et al. describe three grades of AC dislocation. The more recent classification of Rockwood et al. classified the AC dislocations into six types. Allman's and Tossy's classification grades I and II correspond with Rockwood's type I and II. Rockwood, however, made a further subdivision of Allman's and Tossy's grade III into Rockwood type III-VI. 
Types I and II are widely accepted as best managed conservatively $[3,8]$ and there seems to be a consensus that type IV-VI should be treated operatively [7, 9-11]. The best treatment for Rockwood type III dislocations is, despite numerous trials and reviews, still unclear. Some advocate surgical treatment in young physically active adults to maintain good power $[12,13]$, others prefer conservative treatment because of the lower complication rate and recovery time $[1,14]$ and other studies showed no difference in outcome between the conservatively and operatively treated patients $[9,15]$.

Several studies have aimed to investigate the best treatment for type III AC dislocations, conservative versus operative treatment [16-19]. However, no distinction was made in these studies between the different classifications of type III dislocations. This results in several types of AC dislocations within a single study group which gives a skewed result of the outcome of type III dislocations.

Despite previous have studies the debate continues whether patients with Rockwood type III AC injuries should be treated conservatively or operatively. In this study, we will review the current literature and present an overview of the outcome of conservative versus operative treatment of Rockwood type III dislocations.

\section{Materials and Methods}

\section{Search and selection}

The Preferred Reporting Items for Systematic Reviews and Meta-Analyses (PRISMA) guidelines was used to conduct this review [20]. On the 24th of April 2013 we conducted an extensive systematic search of the published literature in the Pubmed, Cochrane library, Embase, Scopus and Cumulative Index to Nursing and Allied Health Literature (CINAHL) databases. We used the search terms 'acromio' and 'clavicular' for domain and 'operative' and 'conservative' for determinant and all variations and combinations of these terms in the title and abstract. Furthermore we added the search term 'III/three/3' in all text fields to be able to specify the search without limiting it. All studies meeting the search terms were included.

Prior to the selection of relevant articles, all double articles were excluded. Two reviewers (KK, AG) independently assessed methodological quality and extracted outcome data. First, title and abstract were screened and articles were excluded by the exclusion criteria shown in Fig. 1. Second, full text copies were obtained and screened of all potentially relevant studies using the criteria shown in Fig. 1. Discrepancies in this exclusion process between the two reviewers was resolved by consensus. The references of the remaining articles were identified using Web of Science and screened using the same criteria.

The articles were independently appraised by two authors (KK, AG) on relevance and validity. Appraisal was performed using the criteria of the Centre for Evidence Based Medicine of the University of Oxford [21]. Articles including more types of Rockwood AC dislocations were selected when the results of the Rockwood type III AC dislocation was separately presented.

\section{Outcomes of interest}

In order to evaluate all published literature we were interested primarily in all objective clinical outcomes (e.g. ConstantMurley score [22], Imatani score [23], Poigenfurst score [15], ULCA score [24], Taft score [25]), radiological assessments and complication rates and secondly all subjective outcomes (e.g. health related quality of life, pain, shoulder function, cosmetic outcome, return to previous work/ sport/activities).

\section{Data analysis}

The preferred analysis was to pool the results of the studies. Homogeneity will be determined with eyeballing. In the case of incomparable outcomes or study groups we will combine comparable patients from different study groups in order to achieve a significant number of patients and perform subgroup analyses. Statistical analysis was performed using SPSS version 20.0 (SPSS Inc. Chicago, Illinois, USA) for Windows. A p-value $<0.05$ was considered significant.

\section{Results}

Search strategy results

Initially 5,815 articles were retrieved from the databases. After excluding doubles and applying the inclusion and exclusion criteria 18 articles were relevant for full text screening. After screening and critically appraising the full text of the remaining articles (Table 1), eight studies were eligible for this study (Fig. 1) [1, 9, 12-15, 26, 27]. None of the articles were randomised trials, six were retrospective cohort studies $[1,12-15,27]$ and two were prospective cohort studies $[9,26]$.

In the absence of homogeneity between the studies, we were not able to pool all the results of the studies. However, to be able to make evident assumptions of the results, we combined patients from different studies with comparable outcomes. 
Fig. 1 Flowchart

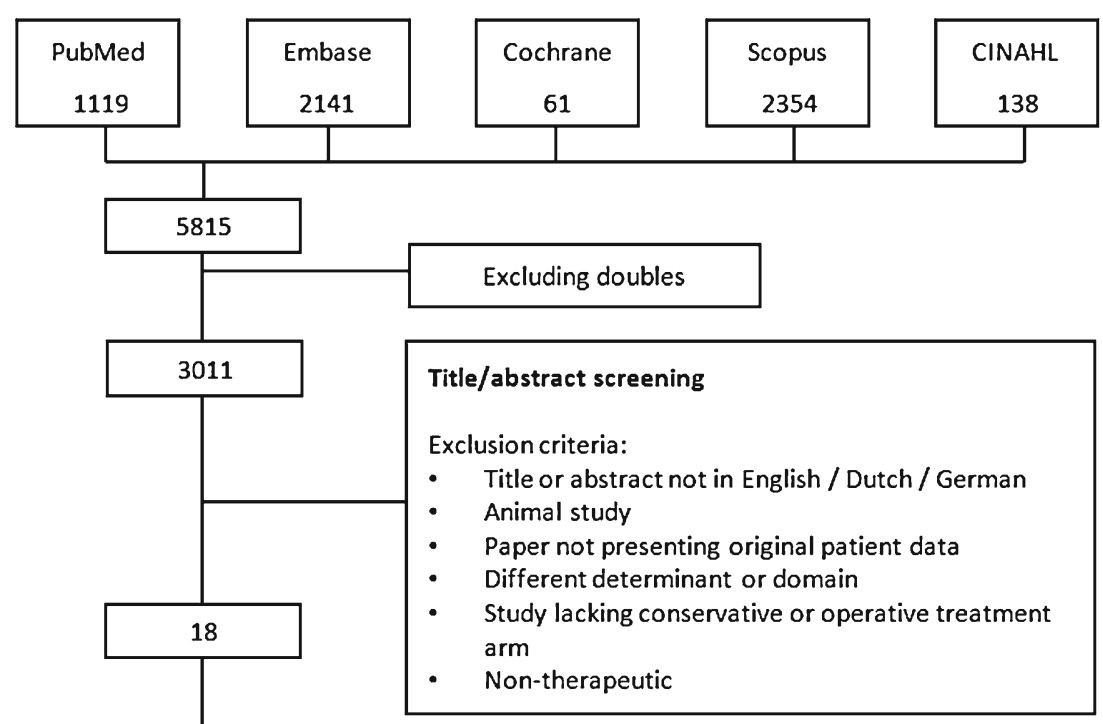

Full text screening

Exclusion criteria:

- Full text not available

- Rockwood type III classification criteria not named in full text

- Results of Rockwood type III not seperately reported in article

- Studies using same patient cohort

\section{Critical appraisal}

- Relevance

- Validity

Table 1 Critical appraisal study designs

\begin{tabular}{|c|c|c|c|c|c|c|c|c|c|}
\hline \multicolumn{3}{|l|}{ Study } & \multicolumn{3}{|l|}{ Relevance } & \multicolumn{4}{|l|}{ Validity } \\
\hline & Desgin & $\begin{array}{c}\text { Sample } \\
\text { size }\end{array}$ & Domain & Determ inant & Outcome & $\begin{array}{l}\text { Random } \\
\text { allocation }\end{array}$ & $\begin{array}{l}\text { Conce aled } \\
\text { tre atment }\end{array}$ & $\begin{array}{c}\text { Complete } \\
\text { data }\end{array}$ & Blinding \\
\hline Calvo [1] & Retro & 43 & & & & $\theta$ & $\theta$ & & $\varnothing$ \\
\hline Cardone [26] & Prosp & 14 & & & & $\theta$ & $\theta$ & & $\theta$ \\
\hline Esen [15] & Retro & 34 & & & & $\theta$ & $\varnothing$ & & $\varnothing$ \\
\hline Fremerey [27] & Retro & 63 & & & & $\theta$ & $\varnothing$ & & $\varnothing$ \\
\hline Gestettner [12] & Retro & 41 & & & & $\theta$ & $\varnothing$ & & $\theta$ \\
\hline Macdonald [14] & Retro & 20 & & & & $\theta$ & $\varnothing$ & & $\varnothing$ \\
\hline Press [13] & Retro & 26 & & & & $Q$ & $Q$ & & $\varnothing$ \\
\hline Prokop [9] & Prosp & 6 & & & & $Q$ & $\theta$ & & $\theta$ \\
\hline
\end{tabular}

Low risk of bias

Moderate risk of bias

High risk of bias

Retro $=$ retrospective, pros $=$ prospective 
Study characteristics

Amalgamated, 142 patients were managed operatively and 105 patients conservatively. Age ranged from 16 to 68 years in the operative group and 14-69 years in the conservative group. The mean follow-up time differed between study groups. With the exception of one study [14], all studies had a minimum follow-up time of 12 months. The follow-up time ranged from 6.3 to 122.8 months in the operative group and 5.7-78 months in the conservative group. A wide range of surgical techniques were described. In three studies the biodegradable PDS cord was used to stabilise the ACjunction $[9,26,27]$. In two studies the (modified) Weaver and Dunn technique was applied $[13,15]$. In the remaining three studies the operative procedure was performed with Bosworth screw fixation, or Steinmann or Knowles pinning [14], an AC-hookplate [12] and the modified Phemister procedure [1]. Postoperative management comprised a sling or bandage.

The conservative treatments consisted of immobilisation management with a sling or bandage. In both groups the treatment was extended with analgesics and physiotherapy when indicated. All these findings are presented in Table 2.

\section{Subgroup analysis}

\section{Shoulder function}

In four studies $[1,9,12,15]$ the objective shoulder function was assessed using an objective scoring system, the Constant score [22], Imatani score [23], Poigenfurst score [15], and Taft score [25]. With the scoring systems patients were scored for pain, function, movement, strength and radiological findings. Because different scoring systems were used we were not able to combine the results and statistically analyse the summarised outcomes in the operatively and conservatively treated patients. The majority of the studies $[1,9,15]$ showed comparable results, i.e. no significant difference between the treatment groups. Gstettner et al. [12] presented a significant difference in Constant score in favour of the operative group, i.e. excellent versus good shoulder function (Table 3).

In three studies $[13,14,26]$ a subjective shoulder function was assessed using a questionnaire, with the items pain, function, stiffness, and cosmetic outcome. The minimum score was one (poor outcomes) and the maximum score was four (excellent outcome). The surgically treated patients scored a higher mean average (3.13) in comparison with the conservative group (2.77; $p=0.406$ ). The difference in subjective shoulder function is mainly caused by the scores of the cosmetic outcome and deformity, which were better in the operative group in the individual studies.
Complications

The complication rate was presented in seven studies $[1,9,12$, $13-15,27]$. Altogether, 49 complications were reported, 32 in the operative and 17 in the conservative group. The most frequently observed complications were deformities, pin migration and a keloid or unattractive scar (Fig. 2). Obviously, infections, pin migration and scar or keloid were only present in the surgical patient group.

A complication was considered clinically relevant when a surgical revision or other additional treatment was indicated. All six patients with this indication were first managed surgically, which suggests that almost $19 \%$ of the complications in the surgical treatment group are considered clinically relevant.

\section{Radiological outcomes}

The radiological outcomes, degree of reduction, osteoarthritis, and calcifications, were examined in three studies $[1,12,27]$. The incidence of osteoarthritis and calcification of the ligament, was higher in the operative group, however not significant $(1.412, p=0.312 ; 1.966, p=0.161)$. In the individual studies, Calvo et al. [1] described a significantly higher incidence of AC osteoarthritis and CC-ligament ossification and a higher number of complete reduction of the dislocation in the operative treatment group. This corresponds with the results of the studies of Gstettner et al. [12] and Fremerey et al. [27], which both showed better anatomical recovery in the operative treatment group.

\section{Cosmetic outcome}

Four studies reported the deformities and cosmetic outcomes $[1,13,14,25]$. The overall evident deformities and the cosmetic complaints about deformities were significantly higher in the conservative treatment group than operative treatment group, respectively, $84 \%$ and $18 \%(p<0.001)$.

\section{Rehabilitation time}

Various outcomes, such as time to return to work, to sports, and recreational activities, were used in the studies to measure the rehabilitation time. In order to evaluate the rehabilitation time we aimed to combine the outcomes into time to return to the normal daily activities. However, all studies used different outcome measurements. Cardone et al. [26] showed that the time to return to the pre-injury sports level was in favour of the surgical group (18.8 versus 26.2 weeks), despite the fact that these patients had a longer rehabilitation time before they were able to return to their sports training at all (6.3 versus 2.4 weeks). Gstettner et al. [12] demonstrated that $4 / 19$ (21\%) patients in the operative treatment group versus $4 / 15$ 
Table 2 Study characteristics

\begin{tabular}{|c|c|c|c|c|c|c|c|c|c|c|c|}
\hline \multirow[t]{2}{*}{ Study } & \multirow[t]{2}{*}{ Design } & \multicolumn{2}{|c|}{$\begin{array}{l}\text { Population } \\
\text { (n) }\end{array}$} & \multicolumn{2}{|c|}{$\begin{array}{l}\text { Gender } \\
(\lesssim / 9)\end{array}$} & \multicolumn{2}{|c|}{$\begin{array}{l}\text { Mean age } \\
\text { (years) }\end{array}$} & \multicolumn{2}{|c|}{$\begin{array}{l}\text { Mean follow-up } \\
\text { (months) }\end{array}$} & \multirow[t]{2}{*}{ Surgical technique } & \multirow[t]{2}{*}{ Conservative technique } \\
\hline & & Surg & Cons & Surg & Cons & Surg & Cons & Surg & Cons & & \\
\hline Calvo et al. [1] & Retro & 32 & 11 & $27 / 5$ & $11 / 0$ & 39.6 & 34.5 & 122.8 & 40.5 & Modified Phemister & $\begin{array}{l}\text { Sling } 2 \text { wks, physio } \\
\text { afterwards }\end{array}$ \\
\hline Cardone et al. [26] & Prosp & 8 & 6 & $8 / 0$ & $6 / 0$ & 26.7 & 29 & 44.8 & 29.5 & $\begin{array}{l}\text { Open reduction, } \\
\text { PDS banding }\end{array}$ & $\begin{array}{l}\text { Sling until comfortable, } \\
\text { physio }\end{array}$ \\
\hline Esen et al. [15] & Retro & 17 & 17 & $12 / 5$ & $12 / 5$ & 46.9 & 40.4 & 36.1 & 29.6 & $\begin{array}{l}\text { Modified Weaver } \\
\text { \& Dunn }\end{array}$ & $\begin{array}{l}\text { AC-bandage, physio } \\
\text { from start }\end{array}$ \\
\hline Fremerey et al. [27] & Retro & 32 & 31 & UK & UK & 35.9 & 33.7 & $6.1 \mathrm{yrs}$ & $6.5 \mathrm{yrs}$ & PDS banding & $\begin{array}{l}\text { Link bandage } 4-6 \text { wks/ } \\
\text { sling 6-12 days, physio } \\
\text { when comfortable }\end{array}$ \\
\hline Gstettner et al. [12] & Retro & 24 & 17 & UK & UK & 37.2 & 36.2 & 32.1 & 36.8 & AC Hook plate & $\begin{array}{l}\text { Sling, physio when } \\
\text { comfortable }\end{array}$ \\
\hline Macdonald et al. [14] & Retro & 10 & 10 & $10 / 0$ & $10 / 0$ & 25 & 31.7 & 6.3 & 5.7 & $\begin{array}{l}\text { Bosworth screw, } \\
\text { Steinmann/Knowles pin }\end{array}$ & Sling immobilisation \\
\hline Press et al. [13] & Retro & 16 & 10 & $12 / 4$ & $9 / 1$ & 30.7 & 49.6 & 32.3 & 33.4 & Weaver \& Dunn & $\begin{array}{l}\text { Sling, physio when } \\
\text { comfortable }\end{array}$ \\
\hline Prokop et al. [9] & Prosp & 3 & 3 & $2 / 1$ & 3 & 37 & 30.3 & 16 & 19.3 & PDS banding & $\begin{array}{l}\text { Gilchrist bandage, physio } \\
\text { when comfortable }\end{array}$ \\
\hline
\end{tabular}

retro retrospective, prosp prospective, surg surgical, cons conservative, UK unknown, physio physiotherapy

(27\%) patients in the conservative treatment group were not able to return to their previous sports level. Furthermore, 1/24 (4.1\%) of the surgically managed patients and 3/17 (17.6\%) of the conservatively managed patients were not able to return to their former level of activity at work. In the study of Press et al. [13] a significantly longer rehabilitation time for work and recreational activities was seen in the surgical group, respectively, 2.6 versus 0.8 months $(\mathrm{p}=0.04)$ and 6.4 versus 3.5 months $(\mathrm{p}=0.02)$.

\section{Discussion}

Despite the fact that many studies have been published regarding the treatment of type III AC dislocations no consensus has yet been reached. A major flaw in the published studies is the lack of use of the Rockwood classification of AC joint injuries [12]. Furthermore, the majority of the studies investigating Rockwood type III include several types of Rockwood injuries or incompatible types of other classifications. This might decrease the informative value of the results in these studies considerably.

In this study we reviewed the current literature and aimed to outline the outcome of conservative versus operative treatment of solely Rockwood type III AC dislocations.

We have performed a broad search on domain and determinant in the title and abstract and have extended the search by adding the search term 'three' and its synonyms in all text fields. We are convinced that adding this search term will not compromise or narrow the search, but decrease the number of articles in any way. In contrast to previous meta-analyses and reviews $[16-19,28]$ we

Table 3 Objective shoulder scoring systems

\begin{tabular}{|c|c|c|c|c|c|c|c|}
\hline Study & $\begin{array}{l}\text { Scoring } \\
\text { system }\end{array}$ & $\begin{array}{l}\text { Max. } \\
\text { points }\end{array}$ & $\begin{array}{l}\text { Operative } \\
\text { score (SD) }\end{array}$ & $\begin{array}{l}\text { Operative } \\
\text { mean outcome }\end{array}$ & $\begin{array}{l}\text { Conservative } \\
\text { score (SD) }\end{array}$ & $\begin{array}{l}\text { Conservative } \\
\text { mean outcome }\end{array}$ & P-value \\
\hline Calvo et al. [1] & Imatani score & 100 & $93.7( \pm 9.9)$ & Excellent & $94.1( \pm 12)$ & Excellent & 0.71 \\
\hline Esen et al. [15] & Poigenfurst score & Excellent & 7 Excellent, 10 good & Good & 9 Excellent, 8 good & Excellent & 0.492 \\
\hline Gstettner et al. [12] & Constant score & 100 & $90.4(12.9)$ & Excellent & $80.7(17.4)$ & Good & $0.029 *$ \\
\hline Prokop et al. [9] & Taft score & 12 & 10.7 & Excellent & 10.3 & Excellent & NA \\
\hline
\end{tabular}

NA not available, SD standard deviation

*Statistically significant $(\mathrm{p}<0.05)$ 
Fig. 2 Complication rate

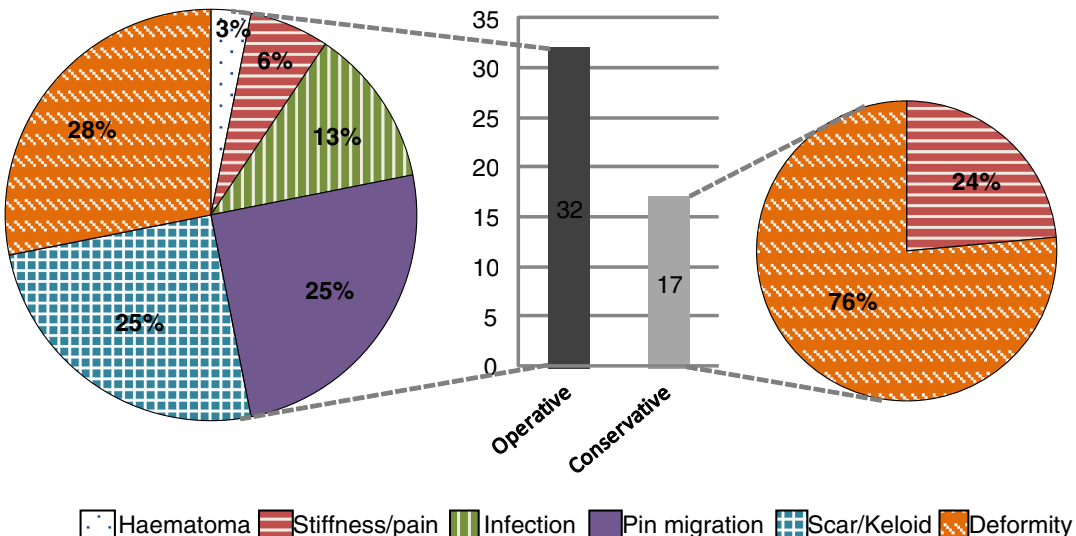

also included German articles. The management of AC injuries has been investigated thoroughly in Germany, therefore including these studies provides a more valid reflection of the current literature.

The most important outcome is the objective shoulder function. In order to evaluate the objective shoulder function multiple objective scoring tools have been developed: Constant-Murley score [22], Imatani score [23], Poigenfurst score [15], ULCA score [24], Taft score [25]. Unfortunately, none of these scoring systems are comparable for analysis because the scores of the different elements in the categories between the scoring system do not match. The majority of the studies showed no difference in the objective shoulder function between the two treatment groups, this is in line with the results of previous reviews [16, 18]. One study [12] showed a significant difference in the objective shoulder function in favour of the operative treatment group, i.e. excellent versus good. However it is unclear what the clinical relevance is in outcome between good and excellent and this is relevant in order to draw conclusions based on this result.

All studies observed a higher complication rate in the operative treatment group, which is an obvious consequence of the invasive procedure. In six surgically treated patients a surgical revision or additional treatment was indicated, and therefore clinically relevant. However, the indication for this decision is not mentioned in the studies. These reoperations might prolong the rehabilitation period and enhance the medical costs.

The radiographic assessments in the studies showed more radiographic abnormalities, e.g. osteophytes, arthrosis/ arthritis and calcifications, after surgical treatment. Though Gstettner et al. [12] reported that the radiographic abnormalities were only clinically symptomatic in one out of the 41 patients. This suggests that a higher number of radiographic abnormalities in the surgical group might not be a valid argument for conservative treatment. This is in accordance with previous studies, which demonstrated that radiological abnormalities after surgery were often not clinically relevant in patients [2, 23, 28-31].
Nowadays, the cosmetic outcome is becoming more and more an important factor. As presented in the results above the cosmetic outcome, defined as a permanent prominent dislocation of the shoulder, is worse in the conservative treatment group. However, complete anatomical correction is not always achieved with surgery $[1,27]$. One should consider the preference of a better cosmetic outcome against the higher complication rate in surgically treated patients.

As in previous reviews [32, 33], the studies were not consistent regarding the rehabilitation time. Cardone et al. [26] and Gstettner et al. [12] presented a better rehabilitation time in the surgically treated patients, especially in the young and physically active adults [26]. Press et al. [13] showed a significantly longer rehabilitation time for the surgical patients. This was also associated with a longer immobilisation period which is according to protocol after the surgical procedure.

There are several open surgical techniques for the treatment of AC dislocations [11, 16-18, 25, 32, 34]. The studies included in this review all used open surgical procedures [1, 9, 12-15, 26, 27]. A novel minimally-invasive technique, presented by Gille et al. [35], showed good results without any complications. Because the outcome after surgery might depend on the chosen surgical treatment, it is important to evaluate the influence of the different surgical treatment on the outcome. Therefore a study which evaluates solely the outcome after different surgical procedures in patients with AC dislocations would be justified.

Furthermore, we have to remark that the follow-up time in the included studies might be too short to evaluate the longterm outcomes of the function of the shoulder or long-term complications. Moreover, the studies do not present any data of the time between the start of physiotherapy or exercises to strengthen the shoulder and the follow-up measurement of the function of the shoulder. These activities are meant to improve the shoulder function and therefore adjustment for the period that a patient received the therapy would be appropriate.

There are a couple of limitations in our study. No randomised trials regarding the treatment of Rockwood type 
III have been published yet. The critical appraisal showed a poor internal validity of the studies and the results of this review are based on level three and four studies. Though we have to bear in mind that these studies are the best available evidence. We only included studies which reported the results of the Rockwood type III AC dislocation separately. Studies which included patients with Rockwood type III, but did not describe the results of type III solely, were not evaluated; this might limit the results of our study.

Furthermore, due to the different scoring systems, we were not able to compare the outcomes of the objective shoulder function in the studies, which we consider as the most important outcome of AC joint injuries.

Moreover, different surgical techniques and conservative treatments were used in the studies. These treatments might also have an influence on the outcome; this should be investigated in an evidence-based manner.

In conclusion, this review showed no conclusive evidence for the treatment of Rockwood type III AC dislocations. Physically active young adults seem to have a slight advantage in outcome when treated operatively. In order to provide evidence for the best treatment in patients with Rockwood type III AC dislocations a randomised trial should be performed with a generalised study population and a longterm follow-up.

Conflict of interest The authors declare that they have no conflict of interest.

\section{References}

1. Calvo E, Lopez-Franco M, Arribas IM (2006) Clinical and radiological outcomes of surgical and conservative treatment of type III acromioclavicular joint injury. J Shoulder Elbow Surg 15:300-305

2. Taft TN, Wilson FC, Oglesby JW (1987) Dislocation of the acromioclavicular joint. J Bone Joint Surg Am 15:300-305

3. Rolf O, Hann von Weyhern A, Ewers A, Boehm TD, Gohlke F (2008) Acromioclavicular dislocation Rockwood III-V: results of early versus delayed surgical treatment. Arch Orthop Trauma Surg 128:1153-1157

4. Sehmisch S, Sturmer EK, Zabka K et al (2008) Results of a prospective multicenter trial for treatment of acromioclavicular dislocation. Sportverletz Sportschaden 22(3):139-145

5. Allman FLJ (1967) Fractures and ligamentous injuries of the clavicle and its articulation. J Bone Joint Surg 49A:774-784

6. Tossy JD, Mead NC, Sigmond HM (1963) Acromio-clavicular separations: Useful and practical classification for treatment. Clin Orthop 28:111-119

7. Rockwood C, Williams G, Young D (1996) Acromioclavicular injuries. In: Rockwood C, Green D, Bucholz R, Heckman J (eds) Fractures in adults, vol 1 ed, 4th edn. Lippincott-Raven, Philadelphia, pp 1341-1413

8. Hootman JM (2004) Acromioclavicular dislocation: Conservative or surgical therapy. J Athl Train 39(1):10-11

9. Prokop A, Helling H, Andermahr J, Mönig S, Rehm K (2003) AC-gelenksprengungen typ tossy III. Der Orthopäde 32(5): $432-436$
10. Post M (1985) Current concepts in the diagnosis and management of acromioclavicular dislocations. Clin Orthop Relat Res 200(200): 234-247

11. Weaver JK, Dunn HK (1972) Treatment of acromioclavicular injuries, especially complete acromioclavicular separation. J Bone Joint Surg Am 54(6):1187-1194

12. Gstettner C, Tauber M, Hitzl W, Resch H (2008) Rockwood type III acromioclavicular dislocation: Surgical versus conservative treatment. J Shoulder Elbow Surg 17(2):220-225

13. Press J, Zuckerman JD, Gallagher M, Cuomo F (1997) Treatment of grade III acromioclavicular separations: operative versus nonoperative management. Bull Hosp Jt Dis 56(2):77-83

14. MacDonald PB, Alexander MJ, Frejuk J, Johnson GE (1988) Comprehensive functional analysis of shoulders following complete acromioclavicular separation. Am J Sports Med 16(5):475-480

15. Esen E, Özturk A, Doğramaci Y, Kanatli U, Bölökbași S (2011) Comparison of surgical treatment and conservative approach for type III acromioclavicular dislocations. Turkiye Klinikleri J Med Sci 31(1):109-114

16. Phillips AM, Smart C, Groom AF (1998) Acromioclavicular dislocation. conservative or surgical therapy. Clin Orthop Relat Res 353(353): $10-17$

17. Smith TO, Chester R, Pearse EO, Hing CB (2011) Operative versus non-operative management following Rockwood grade III acromioclavicular separation: A meta-analysis of the current evidence base. J Orthop Trauma 12(1):19-27

18. Spencer EE Jr (2007) Treatment of grade III acromioclavicular joint injuries: A systematic review. Clin Orthop Relat Res 455:38-44. doi: 10.1097/BLO.0b013e318030df83

19. Tamaoki MJ, Belloti JC, Lenza M, Matsumoto MH, Gomes Dos Santos JB, Faloppa F (2010) Surgical versus conservative interventions for treating acromioclavicular dislocation of the shoulder in adults. Cochrane Database Syst Rev 8:CD007429. doi: 10.1002/14651858.CD007429.pub2

20. Moher D, Alessandro L, Tetzlaff J, Altman DG, for the PRISMA Group (2009) Preferred reporting items for systematic reviews and meta-analyses: the PRISMA statement. BMJ 339:b2535

21. Available at: http://www.cebm.net/index.aspx?o=1157. Accessed 16 September 2013

22. Constant CR, Murley AH (1987) A clinical method of functional assessment of the shoulder. Clin Orthop Relat Res 214:160-164

23. Imatani RJ, Hanlon JJ, Cady GW (1975) Acute, complete acromioclavicular separation. J Bone Joint Surg Am 57(3):328-332

24. Amstutz HC, Sew Hoy AL, Clarke IC (1981) UCLA anatomic total shoulder arthroplasty. Clin Orthop Relat Res 155:7-20

25. Taft TN, Wilson FC, Oglesby JW (1987) Dislocation of the acromioclavicular joint. An end-result study. J Bone Joint Surg Am 69(7):1045-1051

26. Cardone D, Brown JN, Roberts SN, Saies AD, Hayes MG (2002) Grade III acromioclavicular joint injury in Australian rules football. J Sci Med Sport 5(2):143-148

27. Fremerey RW, Lobenhoffer P, Ramacker K, Gerich T, Skutek M, Bosch U (2001) Acute acromioclavicular joint dislocation-operative or conservative therapy? Unfallchirurg 104(4):294-299

28. Larsen E, Bjerg-Nielsen A, Christensen P (1986) Conservative or surgical treatment of acromioclavicular dislocation. A prospective, controlled, randomized study. J Bone Joint Surg Am 68:552-555

29. Thelen E, Rehn J (1976) Acromioclavicularsprengungen Ergebnisse nach operativer und konservativer Versorgung in 162 Fällen. Unfallheilkunde 79:417-422

30. Reichkendler M, Rangger C, Dessl A, Ulmer H (1996) Vergleich und Ergebnis von Schultereckgelenkverletzungen II. und III. Grades. Unfallchirurg 99:778-783

31. Park JP, Arnold JA, Coker TP, Harris WD, Becker DA (1980) Treatment of acromioclavicular separations. Am J of Sports Med $8(4): 251-256$ 
32. Bannister GC, Wallace WA, Stableforth PG, Hutson MA (1989) The management of acute acromioclavicular dislocation. A randomized prospective controlled trial. J Bone Joint Surg Br 71:848-850

33. Sehmisch S, Stürmer EK, Zabka K, Losch A, Brunner U, Stürmer KM, Bauer G (2008) Ergebnisse einer prospectiven Multicenterstudie zur Behandlung der Schultereckgelenksprengung. Sportverl Sportschad 22:139-145
34. Adam FF, Farouk O (2004) Surgical treatment of chronic complete acromioclavicular dislocation. Int Orthop 28(2): $119-122$

35. Gille J, Heinrichs G, Unger A, Riepenhof H, Herzog J, Kienast B, Oheim R (2013) Arthroscopic-assisted hook plate fixation for acromioclavicular joint dislocation. Int Orthop $37(1): 77-82$ 